Technology Studies

online multimedia journal

Культура и технологии

электронный мультимедийный журнал

Journal Homepage: http://cat.ifmo.ru

ISSN 2587-800X

Адрес статьи / To link this article: http://cat.ifmo.ru/ru/2018/v3-i3/163

\title{
Создание детализированных низкополигональных трехмерных моделей для AR-приложения
}

\author{
А.А. Смолин, Ю.А. Трушина \\ Университет ИТМО, Россия \\ smolin@corp.ifmo.ru, yuliatr13@yandex.ru
}

\begin{abstract}
Аннотация. Использование трехмерных моделей в AR-приложениях требует от $3 \mathrm{D}$ художника особых компетенций, основанных на создании контента по определенным требованиям, обусловленным ограничениями, связанными с техническими характеристиками конечного продукта. В данной статье рассматривается применение перспективной технологии дополненной реальности для создания дополнительного контента к настольной игре «Имаджинариум».
\end{abstract}

Ключевые слова: трехмерное моделирование, дополненная реальность, информационные технологии

\section{Введение}

Данный проект был посвящен созданию мультимедийных иллюстраций для настольной карточной игры «Имаджинариум», которая заключается в придумывании ассоциаций к изображенным, нарисованным на специальных карточках. 3D-иллюстрации выступают в роли искусственных элементов дополненной реальности, которые могут сделать интерактивный процесс игры более увлекательным и захватывающим, а придумывание ассоциаций - богатым и интересным.

Процесс создания трехмерного контента для применения в дополненной реальности включает в себя такие этапы, как:

- выбор референсов;

- создание высокополигональной модели (High poly model);

- ретопология: создание низкополигональной модели (Low poly model);

- развертка;

- запекание карт с переносом детализации и текстурирования;

- риггинг, скининг и анимация;

- реализация модели в игровом движке и построение AR-приложения. 


\section{1. Создание 3D модели и подготовка к использованию в AR}

Для создания высокополигональных персонажей на основе двумерных иллюстраций использовалась предназначенная для цифрового скульптинга программа ZBrush, богатый инструментарий которой позволяет достигать высокого уровня детализации (поры, шероховатости поверхности, мельчайшие изгибы, подробно проработанные рельефы и проч.) (рис. 1, рис. 2).
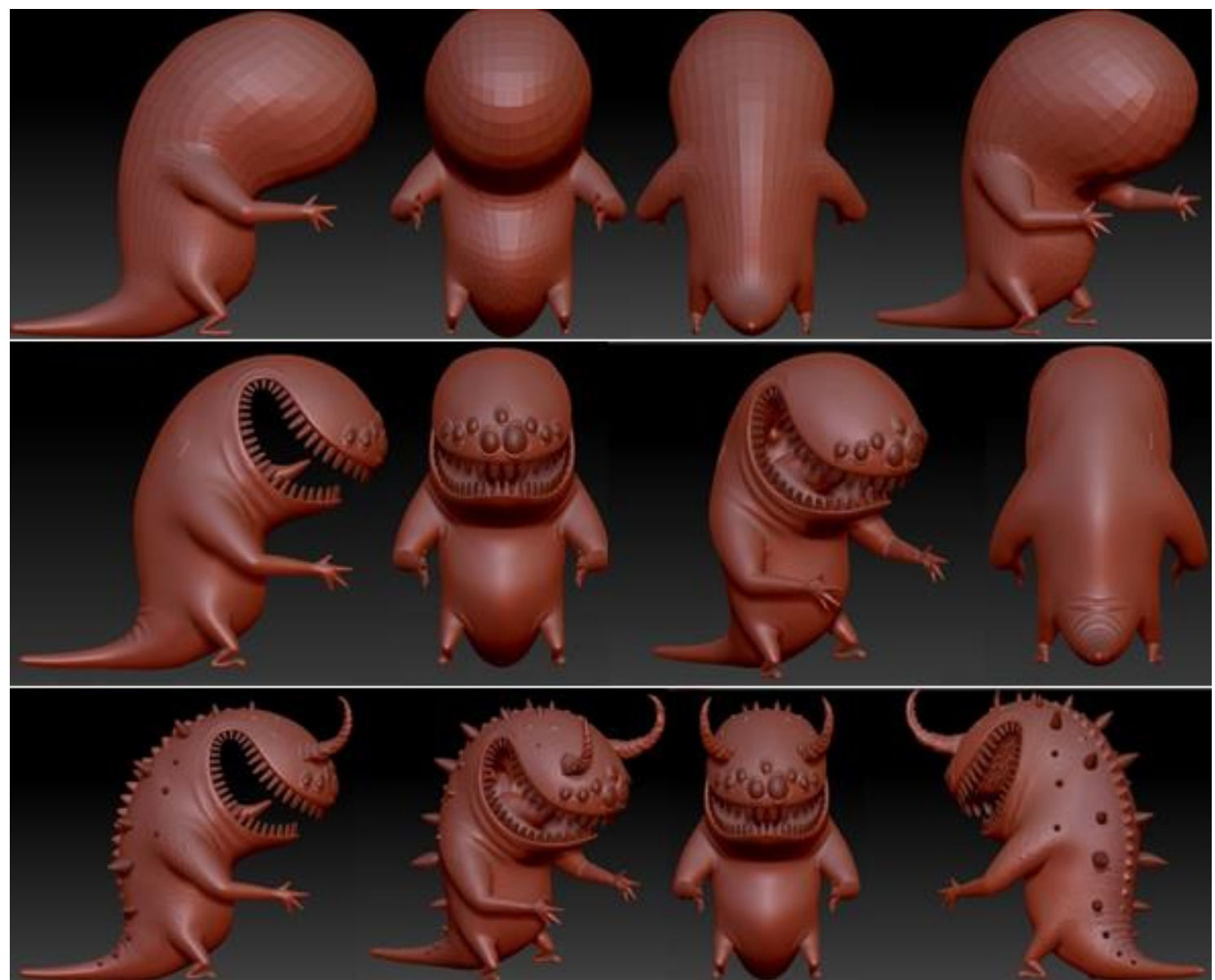

Рис. 1. Модель персонажа на разных уровнях проработки детализации формы

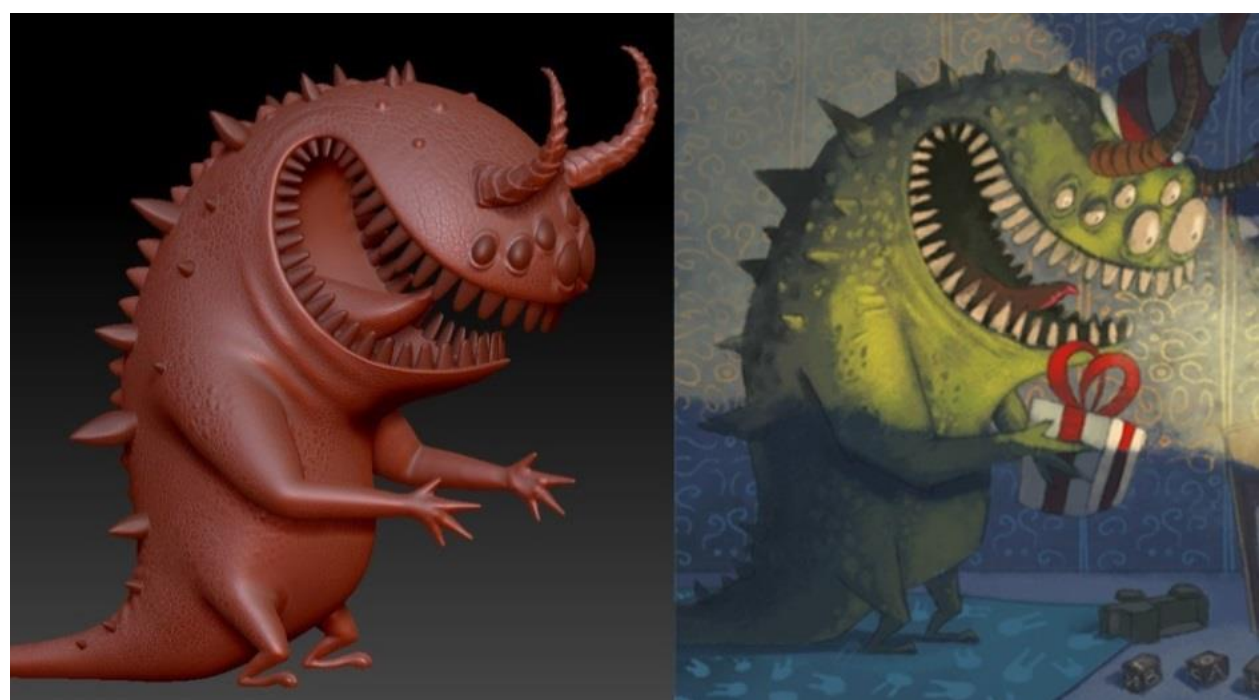

Рис. 2. Готовая НР модель и оригинальное изображение

На основе готовой НP модели делается ретопология [1]: создается ее LP-копия с перераспределенной полигональной сеткой, пригодной для анимации и последующему 
перенесению детализации с HР модели. Упрощенные LP модели необходимы при использовании в приложениях дополненной реальности, так как эти приложения крайне требовательны к используемым ресурсам, следовательно, их необходимо минимизировать именно за счет полигональных характеристик используемых моделей. Следующий необходимый шаг - создание развертки LP модели в текстурных координатах, которая проводилась в программе UVLayout [2] (рис. 3).
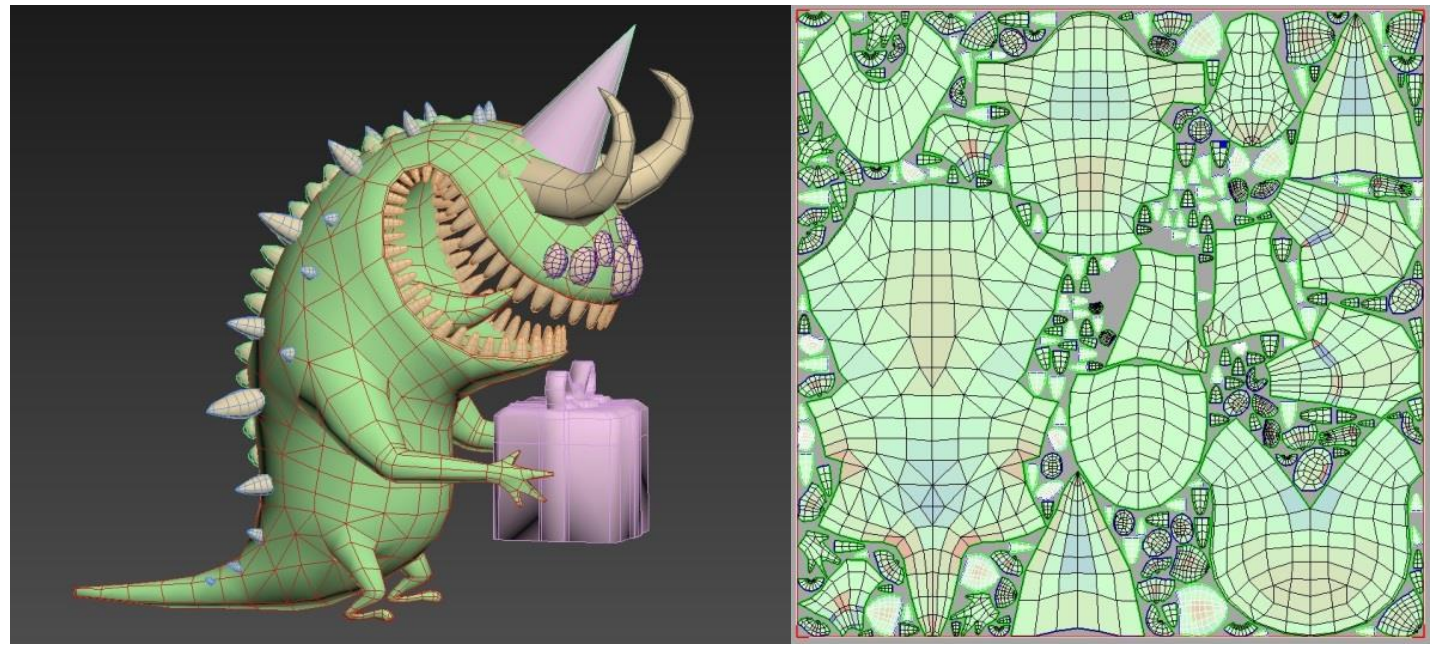

Рис. 3. LP модель и ее развертка

Впоследствии вся детализация, проработанная в HP-варианте модели, переносится на LP модель с помощью технологии Normal Mapping и ряда текстурных карт, определяющих внешний вид готовой модели [3]. Текстурированная LP модель персонажа с перенесенной с ее HPоригинала детализацией, подготовленная к использованию в AR, представлена на рис.4.

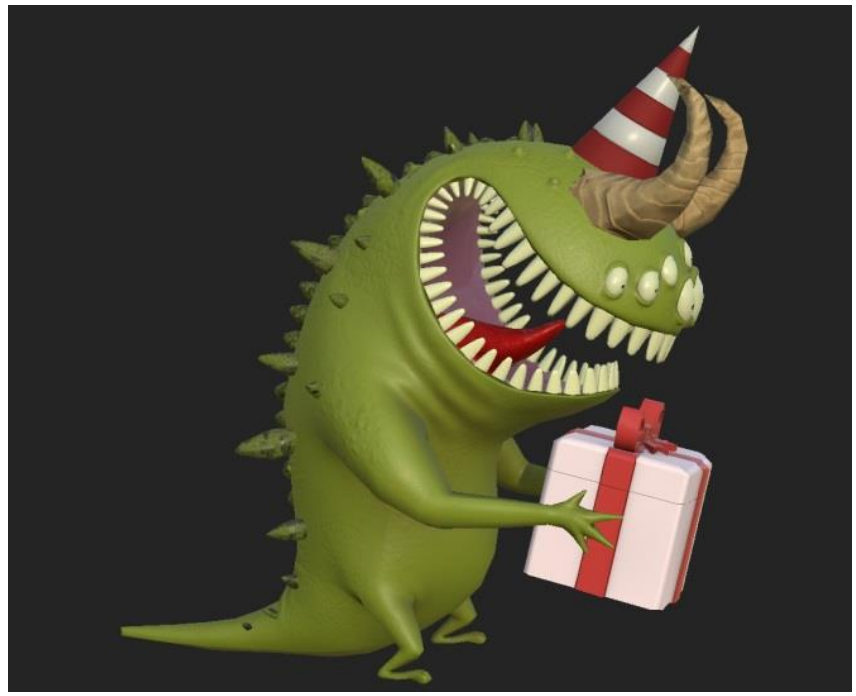

Рис. 4. Подготовленная к AR LP модель

При построении LP модели, ее развертки и запекании текстур должны быть учтены такие факторы, обеспечивающие качественный результат, как:

- минимизация количества полигонов без потери и деформации необходимой формы и силуэта модели;

- уплотнение полигональной сетки на подвижных в результате анимации частях модели;

- специфика создания фасок, скосов, мелких деталей и проч.; 
- распределение групп сглаживания для избегания возникновения градиентов на карте нормалей;

- триангуляция LP перед запеканием;

- грамотная настройка параметров при создании UV-развертки;

- грамотная настройка HP, LP и Cage (ограничивающие проекционные лучи);

- контроль ориентации нормалей по Ү-каналу и т.д.

В случае внимательного и корректного подхода к каждому этапу создания подготовленной LP модели вероятность возникновения проблем и искажений при запекании деталей в карты нормалей минимизируется.

Для моделей, предназначенных для анимации, далее следуют такие этапы, как риггинг (создание системы костей модели) и скининг (привязка полигональной сетки к созданному ригу и ее настройка для осуществления корректных движений модели).

\section{2. Построение AR-приложения}

На данном этапе «заскиненная» анимированная затекстурированная LP модель готова к импорту в игровой движок для построения мобильного приложения. Для этого была использована платформа Unity3D с применением плагина Vuforia [4].

С помощью плагина создается база данных маркеров - выбираемых пользователем изображений для демонстрации на их поверхности 3D моделей. При считывании маркеров камерой мобильных устройств через созданное приложение $3 \mathrm{D}$ модель возникает на содержащемся в базе изображении в качестве элемента виртуальной реальности, дополняющего объективную реальность.

B процессе работы в среде Unity3D тестирование считывания маркеров происходит с помощью веб-камеры. Для возможности считывания изображений камерой мобильных устройств необходимо использование скрипта, предназначенного для настройки фокусировки камеры смартфонов. Ряд инструментов программы позволяет детально настроить создаваемое приложение с точки зрения выбора ОС, названия приложения, его аватара, начальной заставка и прочее. После окончательной установки модели или нескольких моделей на соответствующие маркеры и настройки всех необходимых параметров запускается процесс построения мобильного ARприложения. В результате создается АРК-файл - установочный файл, который необходимо загрузить и установить на мобильном устройстве. Таким образом, при запущенном созданном приложении камера телефона успешно распознает изображение-маркер и накладывает поверх изображения реального мира 3D модель.

\section{Литература}

[1] Retopology workflow in 3ds Max - the how and why [Электронный pecypc] // Autodesk. - URL: http://area.autodesk.com/learning/class4_q2_2013_Todd_Daniele_RetopologyWorkflowIn3dsMaxTheHowAnd Why (дата обращения: 19.09.2018).

[2] User Guide: About UVLayout [Электронный ресурс] // UVLayout. - URL: http://www.uvlayout.com/doc/User_Guide:_About_UVLayout (дата обращения: 19.09.2018).

[3] The toolbag baking tutorial [Электронный pecypc] // Marmoset. - URL: https://www.marmoset.co/posts/toolbag-baking-tutorial/ (дата обращения: 19.09.2018).

[4] Getting started with Vuforia for Unity Development [Электронный pecypc] // Vuforia. - URL: https://library.vuforia.com/articles/Solution/Getting-Started-with-Vuforia-for-Unity-Development ～(дата обращения: 19.09.2018). 


\title{
Creation of low poly 3D models for an AR application
}

\author{
A.A. Smolin, J.A. Trushina
}

ITMO University, Russian Federation

\begin{abstract}
The use of three-dimensional models in AR-applications requires special competencies from a 3D artist based on creating content according to certain requirements, due to limitations related to the technical characteristics of the final product. This article discusses the use of promising technology of augmented reality to create additional content for the board game "Imaginarium".
\end{abstract}

Keywords: three-dimensional modeling, augmented reality, information technology

\section{References}

[1] Retopology workflow in 3ds Max - the how and why [Электронный pecypc] // Autodesk. - URL: http://area.autodesk.com/learning/class4_q2_2013_Todd_Daniele_RetopologyWorkflowIn3dsMaxTheHowAnd Why (дата обращения: 19.09.2018).

[2] User Guide: About UVLayout [Электронный pecypc] // UVLayout. - URL: http://www.uvlayout.com/doc/User_Guide:_About_UVLayout (дата обращения: 19.09.2018).

[3] The toolbag baking tutorial [Электронный pecypc] // Marmoset. - URL: https://www.marmoset.co/posts/toolbag-baking-tutorial/ (дата обращения: 19.09.2018).

[4] Getting started with Vuforia for Unity Development [Электронный pecypc] // Vuforia. - URL: https://library.vuforia.com/articles/Solution/Getting-Started-with-Vuforia-for-Unity-Development (дата обращения: 19.09.2018). 